\title{
EDUCAÇÃO A DISTÂNCIA: Interfaces Motivacionais e Reflexivas das Ações de Formação Continuada
}

\author{
Leandro da Silva Saggiomo ${ }^{1}$ \\ Elaine Corrêa Pereira²
}

\begin{abstract}
RESUMO
Para qualificar o corpo docente que atua nos cursos da modalidade de Educação a Distância (EaD) da Universidade Federal do Rio Grande - Furg - a Secretaria de Educação a Distância (SEaD) desenvolve ações de formação continuada para os sujeitos que atuam nestes cursos. Inseridos nesse contexto encontramos os tutores a distância, responsáveis pelo desenvolvimento, acompanhamento e avaliação dos estudantes. A presente pesquisa de cunho qualitativo visa a identificar as percepções dos tutores a distância do curso de Graduação em Administração modalidade EaD sobre as motivações e reflexões geradas pela participação em atividades de formação continuada. Os pesquisados são tutores a distância que atuaram em duas edições do curso de Administração modalidade a distância. Os dados foram coletados por meio de entrevista semiestruturada e analisados pelo método denominado Discurso do Sujeito Coletivo, proposto por Lefèvre e Lefèvre (2012), o qual se fundamenta a partir da teoria da Representação Social, permitindo desvelar os pensamentos, representações, valores e crenças de uma coletividade. A partir das análises foi gerado o Discurso Coletivizado intitulado "As Ações de Formação em EaD e as Percepções do Tutor a Distância", que embasaram algumas reflexões, demonstrando a análise crítica dos sujeitos investigados sobre o processo de formação continuada da SEaD.
\end{abstract}

Palavras-chave: Formação continuada. Educação a distância. Tutor a distância.

\section{CONTINUING EDUCATION IN DISTANCE EDUCATION: ACTION AND REFLECTION ON THE SKILLS OF THE TUTOR} \begin{abstract}
In order to qualify the faculty that works in the courses Distance Education (EaD) offered by the Federal University of Rio Grande - FURG, the Secretariat of Distance Education (SEaD) develops continuous training actions for the subjects who work in these courses. Inserted in this context we find the distance tutors, responsible for the development, monitoring and evaluation of the students. The present qualitative research aims to identify the perceptions of the distance tutors of the undergraduate course in administration EAD modality on the motivations and reflections generated by the participation in activities of continuous formation. Those surveyed are distance tutors who have worked in two editions of the Distance Learning Administration course. The data were collected through a semi-structured interview and analyzed by the method called Discourse of the Collective Subject, proposed by Lefèvre e Lefèvre (2012), which is based on the theory of Social Representation, allowing to unveil the thoughts, representations, values and beliefs of a collectivity. Based on the analyzes, the Collective Discourse entitled "The Training Actions in Distance Education and the Perceptions of the Distance Tutor" was generated, which supported some reflections, demonstrating the critical analysis of the subjects investigated on the ongoing formation process of SEaD.
\end{abstract}

Keywords: Continuing education. Distance education. Tutor-Professor

RECEBIDO EM: 14/12/2017

ACEITO EM: 10/9/2018

\footnotetext{
${ }^{1}$ Universidade Federal do Rio Grande - Furg. Administrador do Instituto de Matemática, Estatística e Física (Imef/Furg). Professor formador do Curso de Graduação em Administração - EaD - Furg. Mestre e doutorando em Educação em Ciências (PPGEC - Furg). http://lattes.cnpq. br/2372502289018090. Orcid: https://orcid.org/0000-0002-5517-4679. leandrosaggiomo@gmail.com

2 Universidade Federal do Rio Grande - Furg. Instituto de Matemática, Estatística e Física (Imef). Programa Institucional de Bolsas de Iniciação à Docência - Pibid. Grupo de Pesquisa Formação de Professores e Práticas Educativas - Forppe. http://lattes.cnpq.br/7037520500128415. Orcid: https://orcid.org/0000-0002-3779-1403. elainepereira@prolic.furg.br
} 
A Educação a Distância (EaD), modalidade que se efetiva por meio das tecnologias digitais da informação e comunicação (TDICs), configura uma nova maneira de estabelecer relações de ensino e aprendizagem, favorecendo o desenvolvimento dos sujeitos para atuação nos mais diversos ramos profissionais sem a necessidade de frequentar presencialmente a instituição de ensino. Com a expansão e o fortalecimento da EaD, no entanto, novos desafios se configuram na formação de profissionais para atuarem nessa modalidade de ensino.

Nesse contexto de crescente desenvolvimento da EaD, a Universidade Federal do Rio Grande - Furg - por meio da Secretaria de Educação a Distância (SEaD), vem remodelando sua estrutura física e de gestão. Com a crescente demanda dos polos e o aumento dos cursos ofertados, faz-se necessária uma estrutura que possibilite a gestão dos cursos, bem como de todos os processos organizacionais e pedagógicos envolvidos em seu funcionamento.

Novello (2011, p. 74) afirma que a "estrutura da SEaD e da equipe multidisciplinar tiveram diferentes arquiteturas, as quais eram alteradas conforme as demandas que surgiam, especialmente pela ampliação das ações em EaD". A SEaD se configura por uma equipe multidisciplinar, composta por acadêmicos de Graduação e Pós-Graduação e professores e distribuída em nove núcleos. O suporte da equipe multidisciplinar proporciona a produção de Ambientes Virtuais de Aprendizagem (AVA), Objetos Virtuais de Aprendizagem (OVA), simuladores, animações, portais temáticos e material impresso.

Além de todo o suporte técnico que oferece, a SEaD, entendendo seu papel pedagógico, propicia espaços de extensão e pesquisa, a partir da oferta de atividades mensais de formação continuada. Com isso tem o intuito de atender às demandas de qualificação, capacitando os sujeitos envolvidos na EaD da Furg para o uso das TDICs, organizando ciclos de oficinas permanentes. Tais ações visam a proporcionar a formação permanente dos professores e professores-tutores, agregando novos saberes em sua prática pedagógica, introduzindo o uso das TDICs. Para Tardif (2014, p. 36), "a relação dos docentes com os saberes não se reduz a uma função de transmissão dos conhecimentos já construídos. Sua prática integra diferentes saberes com os quais o corpo docente mantém diferentes relações".

Neste contexto de construção coletiva a interação entre os autores do processo formativo da SEaD, bem como dos sujeitos que participam, é fundamental. Compreender como se dão esses processos formativos e a percepção dos tutores a distância que recebem esta formação motivam o estudo. Nosso objetivo consiste em identificar as percepções dos tutores a distância do curso de Graduação em Administração modalidade EaD sobre as motivações e reflexões geradas pela participação em atividades de formação continuada. Para tanto, investigamos à luz da pesquisa qualitativa o entendimento desses sujeitos.

Entendendo que os saberes se constituem a partir da construção de um processo de aprendizagem e de formação (TARDIF, 2014), justifica-se assim a discussão proposta, uma vez que o tutor a distância é sujeito indispensável nos processos de mediação para aprendizagem na EaD. A seguir, destacaremos alguns aspectos importantes sobre a formação em EaD. 


\section{REFLEXÕES SOBRE A FORMAÇÃO CONTINUADA EM EDUCAÇÃO A DISTÂNCIA}

A formação docente na EaD requer um repensar das práticas pedagógicas desenvolvidas em sala de aula. Para tanto é essencial que o professor esteja disposto a novos olhares e horizontes sobre a educação. Geralmente os professores que começam suas atividades na EaD são oriundos dos cursos presenciais, reafirmando a necessidade dessa formação.

Para a SEaD esses profissionais são constante preocupação, no sentido de prepará-los para atuação em EaD. Nesse sentido, concordamos que

[...] tanto nos cursos convencionais como nos cursos a distância, teremos que aprender a lidar com a informação e o conhecimento de formas novas, pesquisando muito e comunicando-nos constantemente. Isso nos fará avançar mais rapidamente na compreensão integral dos assuntos específicos, integrando-os num contexto pessoal, emocional intelectual mais rico e transformador. Assim poderemos aprender a mudar nossas ideias, nossos sentimentos e nossos valores, onde isso se fizer necessário (MORAN et al., 2000, p. 61).

Destacamos que os diferentes papéis do professor na EaD também devem ser levados em consideração nesse âmbito, uma vez que temos docentes atuando em níveis diferentes, ou seja, temos o professor conteudista e o professor formador. Outro sujeito que faz parte deste cenário é o tutor a distância, que em geral trata-se de um profissional pós-graduado e responsável pelo atendimento ao aluno na plataforma, bem como pela mediação entre os alunos e os conteúdos desenvolvidos pelo professor.

Tem-se ainda, no âmbito da docência, o tutor presencial, profissional que permanece durante 20 horas semanais no polo dando atendimento aos alunos que estão vinculados a este, com a incumbência de receber o estudante e orientá-lo quanto às possíveis dificuldades na plataforma Moodle. O trabalho desse docente também propicia espaços de aprendizagem presenciais, por exemplo, os grupos de estudo.

O respeito precisa ser mútuo entre todos os atores que compõem e fazem a Educação a Distância para romper com a dicotomia do aprender e ensinar fragmentadamente, pois embora os profissionais tenham funções diferentes, todas são importantes no processo de ensino-aprendizagem, o que vai ao encontro das palavras de Belloni (2003, p. 81), ao mencionar a "[...] transformação do professor de uma entidade individual em uma entidade coletiva".

A EaD, como qualquer outra modalidade de ensino, requer formação permanente, dialógica e colaborativa das práticas de ensino, assim o processo educativo precisa ser coletivo e compartilhado diariamente. Nesse sentido, coloca-se como grande desafio formar de modo efetivo esses profissionais que, em geral, vêm atuando apenas no ensino presencial (seja em nível de Educação Superior ou da Educação Básica). Assim, percebemos que as novas tecnologias fazem parte das aprendizagens, conforme Souza:

[...] o uso das novas tecnologias amplia as possibilidades do ensino a distância, e podemos acreditar que, pelas possibilidades que oferecem em termos de superação das barreiras impostas pelo tempo e espaço, sua utilização, em futuro não muito distante, tenderá a superar o presencial, principalmente pela abrangência 
que vem sendo almejada pelos projetos institucionais, que têm buscado, cada vez mais, a conquista de mercados que se definem para além das fronteiras nacionais (2003, p. 43).

Além da preocupação com a formação, destaca-se o cuidado com a definição dos papéis e responsabilidades que cada um desses docentes assume e deve realizar em relação ao aluno. Neste contexto, destaca-se a importância das formações permanentes e, acima de tudo, o quanto é necessário que essas formações sejam pensadas com os profissionais e não apenas para eles. A partir desta reflexão, encontramos resposta à provocação feita anteriormente, ou seja, sobre como formar de modo efetivo esses profissionais.

Desse modo, vale mencionar o aprofundamento teórico e a construção de alternativas dialógicas e problematizadoras construídas com a equipe multidisciplinar, o que é fundamental para a formação permanente em Educação a Distância. Na EaD, todos os profissionais envolvidos precisam incorporar os saberes tecnológicos, ou seja, a mediação por meio das TDICs aos saberes pedagógicos. Nesse sentido, Belli ressalta que:

A educação a distância é uma organização de ensino e aprendizagem, na qual estudantes de variadas idades e antecedentes estudam em grupos e/ou individualmente em seus lares ou lugares de trabalho. Usam materiais auto-instrucionais produzidos centralmente através de uma variedade de meios e com comunicação regular e realimentação entre estudantes e professores (1999, p. 13).

Maturana e Varela (1995) estudam a cognição, como se aprende e como se dá a aprendizagem. Na concepção desses autores, a aprendizagem não acontece sozinha, ou seja, na Educação a Distância, se não houver interações com os sujeitos, não há aprendizagem, pois essa ocorre quando há uma mudança estrutural da convivência. Assim, é preciso que os envolvidos no processo trabalhem no coletivo, aceitando o outro como legítimo outro na convivência, contribuindo para a construção da aprendizagem (MATURANA, 2005).

Dessa forma, precisamos estar cientes de que se faz necessário trabalhar coletivamente com todos os atores envolvidos na EaD. Evidentemente, é importante o trabalho coletivo para que a Educação a Distância aconteça de modo dialógico, interdisciplinar, participativo e cooperativo. Nesse sentido,

[...] o diferencial da Furg foi o de acreditar no importante papel que os tutores a distância desempenham nos cursos EaD. Esta constatação fica evidente no empenho da Secretaria de Educação a Distância-SEaD/Furg em realizar a formação continuada de seus tutores e assim, buscar a qualificação destes profissionais (MONTEIRO et al., 2013, p. 14).

Entendendo seu papel formativo nos diversos âmbitos da EaD, a SEaD proporciona periodicamente um espaço de aprimoramento dos conhecimentos oriundos da modalidade, bem como permite um espaço reflexivo sobre a prática educativa dos tutores a distância.

Para o desenvolvimento da pesquisa, apresentaremos a seguir as metodologias utilizadas no estudo, trazendo fragmentos de seu operar e algumas reflexões que emergiram das análises dos dados. 


\section{ORIENTAÇÃO METODOLÓGICA DO ESTUDO}

Quando pensamos nas estratégias metodológicas a serem utilizadas em uma pesquisa, devemos analisar o quanto estas facilitarão o entendimento da complexidade dos fenômenos estudados. Esta é uma pesquisa de delineamento qualitativo, uma vez que a investigação tem por objetivo identificar as percepções dos tutores a distância do curso de Graduação em Administração modalidade EaD sobre as motivações e reflexões geradas pela participação em atividades de formação continuada. Como indica a denominação, "a pesquisa qualitativa possibilita descrever as qualidades de determinados fenômenos ou objetos de estudo" (CORTES, 1998, p. 14). A diferença entre pesquisas quantitativas e qualitativas não é de oposição, mas de ênfase, o que não implica exclusividade (MINAYO, 1998).

Nesta proposta, a pesquisa social qualitativa apresentou-se como o melhor caminho metodológico, considerando que "tem como objetivo a compreensão e a reconstrução da realidade social, especialmente a reconstituição dos sentidos e motivações das ações dos indivíduos, a descrição, explicação e interpretação das ações sociais" (NEVES; CORRÊA, 1998, p. 8). Para desenvolver esta pesquisa propusemos um instrumento de produção de dados aos tutores a distância do curso de Administração modalidade EaD da Furg que atuaram nas suas duas edições.

O critério de escolha foi proposto de modo que fosse possível coletar os discursos desses sujeitos que vêm participando da formação continuada em EaD em um período mínimo de cinco anos. A amostragem foi estabelecida com base em Minayo (1998, p. 196), considerando que "uma amostra ideal em pesquisa qualitativa não atende a critérios numéricos, mas é aquela que reflete as múltiplas dimensões da totalidade". Com essa definição posta, a partir das informações disponibilizadas pela coordenação do curso, chegamos a um total de oito sujeitos. Estes foram convidados para participar da pesquisa, tendo havido o aceite na sua totalidade.

Para obter os dados utilizamos a entrevista semiestruturada, estratégia que Minayo (1998) considera a mais empregada no trabalho de campo, ressaltando o seguinte conceito:

[...] é acima de tudo uma conversa a dois, ou entre vários interlocutores, realizada por iniciativa do entrevistador, destinada a construir informações pertinentes para um objeto de pesquisa, e abordagem pelo entrevistador, de temas igualmente pertinentes tendo em vista este objetivo (MINAYO, 1998, p. 261).

Os registros dos diálogos foram transcritos na sua integralidade, mediante o processo de degravação da mídia em áudio, com base nos critérios de análise de dados qualitativos ancorados no Discurso do Sujeito Coletivo (DSC).

Segundo Lefèvre e Lefèvre (2012), o método DSC consiste basicamente em analisar o material verbal coletado em pesquisas que têm depoimentos como matéria-prima, identificando as Expressões-Chave (ECHs). A partir da análise das semelhanças das ECHs extraímos as Ideias Centrais (IC) que serão discutidas com base nas Ancoragens (ACs). Para Sales, Souza e John,

[...] estruturalmente, o DSC se organiza a partir da utilização de figuras metodológicas designadas como: ancoragem; ideia central; expressões-chave e o discurso do sujeito coletivo, propriamente dito. Os significados dessas figuras ou etapas de um 
procedimento de análise dão a noção de um processo de apreensão de significados que surgem no conjunto das falas, as quais exibem um pensamento coletivo ou a representação do grupo sobre dado tema ou questão (2007, p. 132).

As Expressões-Chave (ECHs) são transcrições literais de partes ou trechos do discurso que devem ser destacadas (sublinhadas, iluminadas, coloridas) que revelam a essência do depoimento, ou seja, do conteúdo discursivo a ser analisado. "É com a matéria-prima das expressões que se constroem os Discursos do Sujeito Coletivo" (LEFÈVRE; LEFÈVRE, 2005, p. 17).

As Ideias Centrais (IC) limitam-se a um nome ou expressão linguística que descreve, de forma sintética e precisa, o sentido do conjunto de ECH analisado, de onde terá origem o DSC.

As ACs representam uma figura metodológica sob inspiração de uma dada teoria ou ideologia que o pesquisador julga necessária para enquadrar situações específicas. As ACs nem sempre estão presentes nos discursos.

Tal metodologia caracteriza-se por dar uma só voz a uma coletividade, dando uma forma una no conjunto de individualidades semânticas que compõem o imaginário social. A técnica visa a não separar os discursos individuais dos coletivos, mas uni-los em um só discurso coletivo. Como Lefèvre e Lefèvre (2012) explicam, é uma soma de pensamentos na forma de conteúdo discursivo.

Participaram do estudo oito tutores a distância, gerando oito discursos individuais como matéria para análise. Foi previamente comunicado aos respondentes que as informações geradas naquela conversação seriam mantidas sob sigilo, para preservação da identidade de cada entrevistado.

A partir do agrupamento das ECHs dos vários depoimentos, e analisando as ICs de sentido equivalente dessas ECHs, caracteriza-se, segundo a técnica, um só sujeito que representa a voz da coletividade. Dessa forma é construído o Discurso Coletivizado (DC), escrito na primeira pessoa do singular, a partir da reunião das ECHs interligadas por conectores a fim de dar coesão ao DC. Com base nas ACs, que fornecem o aporte para a fundamentação teórica, é analisado o DC.

\section{ANÁLISES E DISCUSSÕES}

A presente investigação procurou identificar as percepções dos tutores a distância do curso de Graduação em Administração modalidade EaD sobre as motivações e reflexões geradas pela participação em atividades de formação continuada em EaD, à luz do método do DSC. Para compreendermos a construção dos DCs, a seguir apresentamos o Quadro 1, chamado de Instrumento de Análise de Discurso (IAD), o operar da técnica.

Os fragmentos dos depoimentos foram organizados nas células da primeira coluna, classificados como ECH. Estas foram agrupadas por semelhança, dando origem às ICs para que se pudesse registrar de uma forma autêntica os sentidos dos discursos analisados. A terceira coluna contém as ACs, ou seja, temas norteadores para estabelecer uma reflexão teórica com os discursos. 
Quadro 1 - Instrumento de Análise de Discurso - IAD - O operar da técnica DSC

\begin{tabular}{|c|c|c|}
\hline EXPRESSÕES-CHAVES & $\begin{array}{l}\text { IDEIAS } \\
\text { CENTRAIS }\end{array}$ & ANCORAGENS \\
\hline $\begin{array}{l}\text { formação continuada visa a capacitar os tutores para atuarem na Educa- } \\
\text { ção a Distância e te atualizar em diversas áreas que vão contribuir para a } \\
\text { melhoria da tua resposta, tua explicação para o aluno. Lembro da parte } \\
\text { da plataforma do Moodle, algumas oficinas de processos de avaliação na } \\
\text { Educação a Distância que foram importantes para dar alguma visão que eu } \\
\text { desconhecia. } \\
\text { Até a questão de português eu tive, da escrita, padronização de resposta. } \\
\text { Eles fizeram bem prática e isso deu um retorno ao aluno e a partir desse } \\
\text { retorno eles verificaram se a pessoa foi seca, se era preciso mudar a lingua- } \\
\text { gem, se tinha que ser formal, mas não rígida para o aluno não entender aqui- } \\
\text { lo como uma ofensa e achei isso importante. Participei da oficina feedback, } \\
\text { um evento que teve no Cidec, que foram dois dias, "encontro para ações } \\
\text { em EaD da Furg", participei de dois encontros semestrais, vinham pessoas } \\
\text { palestrar sobre o assunto, eu achei bem interessante. } \\
\text { atingiria o objetivo de auxiliar o aluno nesse estudo. } \\
\text { melhorou bastante na minha linguagem, para dar feedback, para respon- } \\
\text { der mensagens, para tentar motivar a participação, para motivar que res- } \\
\text { pondam às questões, que participem, e isso melhorou bastante nas ofici- } \\
\text { nas de como interagir com eles. } \\
\text { temática da avaliação no sistema de EaD no meu ponto de vista ela foi } \\
\text { extremamente importante pra contribuir no meu desempenho como tutor } \\
\text { a distância, por que ela me alertou sobre algumas formas de como acom- } \\
\text { panhar a evolução do aluno, o interesse do aluno. } \\
\text { concluo que a formação continuada pra mim foi melhor na parte técnica. }\end{array}$ & Capacitação & $\begin{array}{l}\text { Formação } \\
\text { Continuada }\end{array}$ \\
\hline $\begin{array}{l}\text { Eu sei que a formação continuada é obrigatória e na Sead tem uma equipe } \\
\text { de professores que planeja e executa esta formação. } \\
\text { certo momento que começou a ficar repetitivo, por exemplo, todos os anos } \\
\text { eles nos chamavam para a primeira oficina para conhecer o Moodle, mas } \\
\text { eu já conheço o Moodle, nossos alunos de Administração não têm a cultura } \\
\text { de usar algumas coisas que o Moodle oferece e que são incentivadas, ficam } \\
\text { muitas coisas voltadas para isso. Penso que o processo de formação conti- } \\
\text { nuada é importante, mas precisa ser sempre reformulado e aprimorado a } \\
\text { fim de não se tornar repetitivo e cansativo. } \\
\text { estar assistindo um curso que não é a sua área para nós que trabalhamos } \\
\text { com disciplinas mais práticas no início era bem cansativo, nosso curso não } \\
\text { tem disciplinas de Licenciatura então as práticas pedagógicas que toma- } \\
\text { vam conta das oficinas eram bem maçantes. }\end{array}$ & $\begin{array}{l}\text { Obrigatorie- } \\
\text { dade }\end{array}$ & Legalidade \\
\hline $\begin{array}{l}\text { Destaco que lá no início, alguns tutores mais experientes falavam sobre } \\
\text { a extrema formalidade na conversa com os alunos, nunca concordei com } \\
\text { isso, pois não somos operadores de telemarketing, no meu entendimento } \\
\text { era preciso me aproximar dos alunos e não me distanciar e tanta formali- } \\
\text { dade não ajudava nesse processo. } \\
\text { a formação não é só o curso, são as conversas, a reunião periódica com o } \\
\text { professor. Dependendo do professor da disciplina que estiver trabalhando, } \\
\text { a metodologia que cada um trabalha, contribuem na tua formação, pois } \\
\text { acho que nossas conversas entre tutores e professores do curso sempre } \\
\text { são muito proveitosas. Dentro dessas conversas é que se consegue ver } \\
\text { que o aluno de determinado polo tem maior dificuldade e averiguar o que } \\
\text { se pode fazer com ela, qual o tipo de mensagem que precisamos mandar, } \\
\text { como fazemos isso? } \\
\text { hoje eu tenho mais facilidade para dar um feedback, mas daqui a pouco } \\
\text { surgiu alguma coisa muito específica que eu não sei muito bem como lidar, } \\
\text { tem a coordenação, tem todo esse conjunto, essas ideias compartilhadas } \\
\text { nos dão uma visão de que talvez nós sozinhos não teríamos. Então acho } \\
\text { importante as reuniões serem mais focadas no grupo do curso }\end{array}$ & $\begin{array}{l}\text { Troca de Expe- } \\
\text { riências }\end{array}$ & $\begin{array}{l}\text { Saberes Expe- } \\
\text { rienciais }\end{array}$ \\
\hline
\end{tabular}

Fonte: Dados da pesquisa. 
No Quadro 2 está representado o DC denominado "As ações de formação em EaD e as Percepções do Tutor a Distância". O discurso foi construído pelo agrupamento das $\mathrm{ECHs}$ dos vários depoimentos que apresentavam as ICs de sentido equivalente, caracterizando, segundo a técnica, um só sujeito que representasse a voz da coletividade. Desse modo, a redação do discurso se expressa na primeira pessoa.

\title{
Quadro 2 - Discurso Coletivizado 1 (DC1) - As ações de formação em EaD e as percepções do tutor a distância
}

\begin{abstract}
A formação continuada visa a capacitar os tutores para atuarem na Educação a Distância e te atualizar em diversas áreas que vão contribuir para a melhoria da tua resposta, tua explicação para o aluno e é obrigatória na Sead. Tem uma equipe de professores que planeja e executa esta formação. Lembro da parte da plataforma do Moodle, algumas oficinas de processos de avaliação na Educação a Distância que foram importantes para dar alguma visão que eu desconhecia. Participei da oficina feedback, eu achei bem interessante, eles fizeram bem prática. Até a questão de português eu tive, da escrita, padronização de resposta e isso deu um retorno ao aluno e a partir desse retorno eles verificaram se a pessoa foi seca, se era preciso mudar a linguagem, se tinha que ser formal, mas não rígida para o aluno não entender aquilo como uma ofensa e achei isso importante. Destaco que lá no início alguns tutores mais experientes falavam sobre a extrema formalidade na conversa com os alunos, nunca concordei com isso, pois não somos operadores de telemarketing, no meu entendimento era preciso me aproximar dos alunos e não me distanciar e tanta formalidade não ajudava nesse processo. Mas a formação não é só o curso, são as conversas, a reunião periódica com o professor. Dentro dessas conversas é que se consegue ver que o aluno de determinado polo tem maior dificuldade e averiguar o que se pode fazer com ela, qual o tipo de mensagem que precisamos mandar, como fazemos isso? Essas ideias compartilhadas nos dão uma visão de que talvez nós sozinhos não teríamos, por isso acho importante as reuniões serem mais focadas no grupo do curso. Mas certo momento que começou a ficar repetitivo, por exemplo, todos os anos eles nos chamavam para a primeira oficina para conhecer o Moodle, mas eu já conheço o Moodle, nossos alunos de Administração não têm a cultura de usar algumas coisas que o Moodle oferece e que são incentivadas, ficam muitas coisas voltadas para isso. Penso que o processo de formação continuada é importante, mas precisa ser sempre reformulado e aprimorado a fim de não se tornar repetitivo e cansativo, pois estar assistindo um curso que não é a sua área para nós que trabalhamos com disciplinas mais práticas no início era bem cansativo, nosso curso não tem disciplinas de Licenciatura então as práticas pedagógicas que tomavam conta das oficinas eram bem maçantes. A temática da avaliação no sistema de EaD no meu ponto de vista ela foi extremamente importante pra contribuir no meu desempenho como tutor a distância, por que ela me alertou sobre algumas formas de como acompanhar a evolução do aluno, o interesse do aluno, mas concluo que a formação continuada pra mim foi melhor na parte técnica.
\end{abstract}

Fonte: Autoria própria.

A partir do discurso coletivizado produzido foram geradas diversas reflexões sobre os olhares dos tutores a distância acerca das ações de formação em EaD promovidas pela SEaD. Com isso, buscamos dialogar sobre os temas emergentes nas análises.

O Decreto n. 5.622, no artigo 10 (BRASIL, 2005) contempla a fluência tecnológica quando destaca a "utilização de meios e tecnologias de informação e comunicação" na Educação a Distância. Da mesma forma, os Parâmetros Curriculares Nacionais (BRASIL, 1999, p. 108) destacam a importância de "saber utilizar diferentes fontes de informação e recursos tecnológicos para adquirir e construir conhecimentos".

O desenvolvimento da fluência deve ser estimulado a partir das oportunidades de compreensão de conceitos ligados a recursos tecnológicos e à formação da capacidade de colaboração para resolução de problemas. Para Mansell (2015), a formação 
[...] deve envolver competências conceituais, tais como pensamento crítico, abordagens inovadoras para resolução de problemas, competências práticas para navegar em ambientes de mídia e informação e competências tais como interação via redes sociais, cidadania digital e habilidades para interação intercultural (MANSELL, 2015, p. 6).

Neste contexto, os tutores a distância relatam as formações promovidas pela SEaD que se tornaram de alguma maneira mais expressivas e presentes no seu fazer pedagógico. Destacamos as formações em Moodle, Feedback, Escrita e Avaliação na EaD, conforme recorte:

Lembro da parte da plataforma do Moodle, algumas oficinas de processos de avaliação na Educação a Distância que foram importantes para dar alguma visão que eu desconhecia. Participei da oficina feedback, eu achei bem interessante, eles fizeram bem prática. Até a questão de português eu tive, da escrita, padronização de resposta e isso deu um retorno ao aluno e a partir desse retorno eles verificaram se a pessoa foi seca, se era preciso mudar a linguagem, se tinha que ser formal, mas não rígida para o aluno não entender aquilo como uma ofensa e achei isso importante. Destaco que lá no início, alguns tutores mais experientes falavam sobre a extrema formalidade na conversa com os alunos, nunca concordei com isso, pois não somos operadores de telemarketing, no meu entendimento era preciso me aproximar dos alunos e não me distanciar e tanta formalidade não ajudava nesse processo (DC 1).

O Moodle é um sistema de gerenciamento para criação de curso on-line. Caracterizado por ser um software livre de apoio à aprendizagem, seu desenvolvimento é de forma colaborativa por uma comunidade virtual, a qual reúne programadores, designers, administradores, professores e usuários do mundo inteiro e está disponível em diversos idiomas. A plataforma vem sendo utilizada não só como ambiente de suporte à Educação a Distância, mas também como apoio a cursos presenciais, formação de grupos de estudo e treinamento de professores.

Na EaD da Furg, o Moodle é o AVA, utilizado no desenvolvimento dos cursos. Por conta disso, esta ferramenta é o primeiro contato do tutor com a modalidade de ensino, pois será a partir desse ambiente que será estabelecido o diálogo com o aluno.

Outra temática abordada nas oficinas considerada pelos pesquisados como de extrema relevância para a atuação na tutoria foi o feedback. Segundo Moore e Kearsley (2007, p. 251), fatores determinantes do sucesso da EaD são a quantidade e a qualidade dos diálogos entre os professores e os estudantes, tendo como objetivo a promoção da autonomia de aprendizagem. É a partir do feedback que se estabelece o diálogo dos cursistas com o tutor.

Assim, esta ação pode ser descrita como qualquer procedimento ou comunicação realizada para informar o aprendiz sobre a acuidade de sua resposta, geralmente relacionada a uma pergunta instrucional. Este processo de diálogo se estabelece a partir da escrita, outro tema reforçado no DC 1, quando os tutores a distância relatam suas experiências vividas nas oficinas. 
Para Nogueira (2010), a transformação da linguagem oral em linguagem escrita, no intuito de orientar uma interação entre pessoas separadas geograficamente, seria uma Comunicação Mediada por Computador (CMC). Uma comunicação que se efetiva de forma interativa na Internet pressupõe, como nos mostra Silva (2006, p. 79), "múltiplas redes articulatórias de conexões e liberdade de trocas, associações e significações".

Temos outros fatores envolvidos nesse contexto, pois a CMC pode acontecer de forma síncrona ou assíncrona e, tratando-se especificamente de educação, é preciso considerar a produção de sentidos que a linguagem escrita assume no lugar da linguagem oral. As ferramentas síncronas caracterizam-se por permitir a realização de uma comunicação virtual em tempo real, semelhante a uma conversa, quando os participantes devem estar conectados simultaneamente. Já as ferramentas assíncronas permitem o diálogo em tempos distintos, por exemplo, os fóruns.

Os pesquisados relatam também os aprendizados construídos nas formações sobre avaliação na EaD. Segundo Oliveira (2006):

Na Educação a Distância, a avaliação é pensada enquanto sistema, ou seja, ela compõe o sistema de EaD conjuntamente com os sistemas de gestão, sistema de tutoria (acompanhamento e apoio ao estudante), sistema de comunicação e tecnologia, sistema de elaboração de material didático (impresso, mídias, hipertexto, digital, etc.), permitindo, assim, que se avalie a proposta curricular e o impacto socioeducacional dos cursos oferecidos. Enquanto sistema, os elementos da avaliação são específicos aos sistemas da EaD (OLIVEIRA, 2006, p. 4-5).

Assim, o processo de avaliação pode ser concebido como um sistema regulador em EaD (no sentido de diagnóstico e possibilidade de redefinição, reelaborações e tomadas de decisão), pois ele é capaz de oferecer um retorno acerca dos impactos do sistema de EaD como um todo, na aprendizagem do estudante e acerca do "sentimento de estar em relação" com os sujeitos envolvidos no processo formativo, com os meios utilizados, desenvolvendo, assim, autonomia no processo de aprendizagem.

Nesse sentido, as tecnologias devem ser entendidas como elemento mediador do processo de ensino-aprendizagem e a formação de professores deverá contemplar um currículo inovador e criativo, possibilitando ao educador situar-se criticamente nesse contexto tecnológico, estabelecendo conexões entre teoria e prática. Sendo assim, a formação docente possibilitou a construção de conhecimentos tendo como suporte as ferramentas disponibilizadas pelas tecnologias digitais.

Segundo os pesquisados, no entanto, a formação continuada está para além dos processos de instrumentalização de ferramentas da EaD, bem como dos encontros que desencadeiam temáticas problematizadoras da ação em EaD. Os professores tutores entendem que o encontro com o professor titular da disciplina, bem como a troca de experiências com o grupo de tutores da mesma área de atuação, contribuem de maneira prática para a atividade que desenvolvem. Nesse sentido, trazemos o recorte do DC 1 , que relata explicitamente a prática cotidiana dos sujeitos estudados em confronto com as condições da profissão.

Mas a formação não é só o curso, são as conversas, a reunião periódica com o professor. Dentro dessas conversas é que se consegue ver que o aluno de determinado polo tem maior dificuldade e averiguar o que se pode fazer com ela, qual o tipo 
de mensagem que precisamos mandar, como fazemos isso? Essas ideias compartiIhadas nos dão uma visão de que talvez nós sozinhos não teríamos, por isso acho importante as reuniões serem mais focadas no grupo do curso (DC 1).

Tardif (2014) contribui na reflexão desta constatação destacando:

Os saberes experienciais surgem como núcleo vital do saber docente, núcleo a partir do qual os professores tentam transformar suas relações de exterioridade com os saberes em relações de interioridade com sua própria prática. Neste sentido os saberes experienciais não são saberes como os demais; são, ao contrário, formados de todos os demais, mas retraduzidos, "polidos" e submetidos às certezas, construídos na prática e na experiência (p. 54).

Por meio destes saberes o tutor interage com os outros saberes, pois o saber docente se constitui de uma construção, do saber de alguém sobre alguma coisa ou trabaIho; sua mobilização possibilita reconstruir suas habilidades bem como suas competências profissionais. Deste modo, o saber é a experiência docente em sua relação com o meio, com o ambiente formativo, com os alunos.

Por isso o saber docente é essencialmente heterogêneo, pois a prática docente também é heterogênea por estar inserida em um contexto multicultural. Essa heterogeneidade, segundo Tardif (2014, p. 54), "não se deve apenas à natureza do saber presente; ela decorre também da situação do corpo docente diante dos demais grupos produtores e portadores de saberes e das instituições de formação".

Diante desta perspectiva apontada pelo coletivo de professores tutores, concordamos com Nóvoa (1999, p. 26) quando este reflete que a "formação do professor é, provavelmente, a área mais sensível das mudanças em curso no sector educativo: aqui não se forma apenas profissionais; aqui produz-se uma profissão". Assim, acreditamos que um professor bem instruído já é um dos pilares para um ensino de qualidade. Também corroboramos com Lopes (2010), ao afirmar que

[...] a relação de reciprocidade entre a formação para as tecnologias e suas implicações no habitus do professor ganha novas matizes quando considerada no âmbito de cursos desenvolvidos na modalidade a distância, haja vista a presença indispensável das tecnologias e a circulação de um conjunto de saberes a elas inerentes nesses novos tempos e espaços de aprendizagem (LOPES, 2010, p. 283).

Assim, a interação entre os conhecimentos inerentes às TDICs, bem como as relações estabelecidas entre os saberes do professor, trazem a solidez necessária para o desenvolvimento da proposta pedagógica do curso ora trabalhado. Os professores tutores, contudo, mesmo reconhecendo a importância dos processos formativos deixam registrado em sua fala a questão da obrigatoriedade de sua participação, conforme DC 1 quando afirmam: "Eu sei que a formação continuada é obrigatória na SEaD".

Dessa forma, procuramos entender qual a orientação institucional quanto à obrigatoriedade da formação continuada em EaD. Buscando os documentos legais para amparo da ação, trazemos um fragmento do documento denominado Anexo I do Edital de Seleção de Tutores a Distância da Furg, no qual é especificada esta obrigatoriedade, solicitando a ciência do futuro tutor já no processo seletivo: 
A carga horária total de tutoria é de 20 horas semanais, sendo que, destas, 8 horas são destinadas à reunião com o professor da disciplina e 4 horas para a formação continuada. A formação continuada é obrigatória, sendo definida, previamente, através de cronograma (FURG, 2016, p. 7).

Durante as entrevistas os pesquisados não aprofundaram o tema obrigatoriedade, mas suas expressões nos demonstraram um descontentamento com essa prática. Para compreender esta impressão do pesquisador buscamos algumas leituras sobre obrigatoriedade da formação docente. Assim, compartilhamos do pensamento de Contreras (2002), quando observa que os professores são controlados em suas atividades, preestabelecidas em competências, conceito que está substituindo o de saberes e conhecimentos, acarretando ônus para os professores, uma vez que lhe retira a condição de sujeito do conhecimento.

Outro assunto detectado nas análises foi a repetição de temas nas formações continuadas, como demonstra o excerto a seguir, extraído do DC 1.

Penso que o processo de formação continuada é importante, mas precisa ser sempre reformulado e aprimorado, a fim de não se tornar repetitivo e cansativo, pois estar assistindo um curso que não é a sua área para nós que trabalhamos com disciplinas mais práticas no início era bem cansativo, nosso curso não tem disciplinas de Licenciatura, então as práticas pedagógicas que tomavam conta das oficinas eram bem maçantes (DC 1).

Nesse discurso os professores tutores reforçam a questão da repetição de temas problematizadores, abordagens que já haviam sido trabalhadas anteriormente e das quais os sujeitos obrigatoriamente deveriam participar novamente. Além disto, os pesquisados muitas vezes não se reconheceram no espaço formativo, visto que obrigatoriamente "participavam" de discussões de temas que não mostravam proximidade com sua ação profissional, bem como com o conhecimento da área de atuação de sua prática docente.

A partir disso verificamos que os Referenciais para a Formação dos Professores (RFP) (BRASIL, 1999) reconhecem o quadro de insuficiência e debilidades no que se refere ao campo político-administrativo, organizacional e metodológico da formação continuada:

1- [...] falta de articulação entre várias instâncias de gestão do sistema, a descontinuidade dos projetos e programas de um governo para outro, a pressa com que as ações são planejadas e realizadas para atender às limitações do tempo político das administrações, a falta de incentivos salariais ou institucionais para que os professores participem de programas de formação e a inexistência de tempo previsto na jornada de trabalho e no calendário escolar para formação em serviço [...].

2- [...] não se planeja de forma articulada ações extensivas e de profundidade, priorizando-se a alternativa de grandes eventos pontuais, cujo efeito é bastante relativo e discutível [...] não há como considerar suas reais necessidades e avanços em atividades desse tipo. 
É importante uma adequação das propostas de ações de formação às necessidades impostas na prática docente a fim de solucionar problemas e dificuldades emergentes no campo da formação continuada e à superação de modelos e práticas recorrentes, pois há urgência de adequações pontuais, atendendo aos anseios da profissão, uma vez que se faz presente

[...] a inexistência de mecanismos de acompanhamento contínuo da prática pedagógica, de avaliação periódica dos resultados das ações desenvolvidas e de identificação de demandas de formação, colocadas pelas dificuldades que encontram os professores no exercício profissional, [que] prejudica a qualidade de formação, uma vez que estes são instrumentos de avaliação fundamentais para o planejamento e redimensionamento dos programas (BRASIL, 1999, p. 47).

Com isto, o Ministério da Educação reconhece as necessidades de adequação das ações formativas aos contextos de atuação profissional, institucionalizando a formação continuada de professores no país com a criação da Rede Nacional de Formação Continuada (BRASIL, 2005), em cuja composição figuram o próprio MEC, os Sistemas de Ensino e os Centros de Pesquisa e Desenvolvimento da Educação. A regularização desta formação está colocada nos seguintes termos:

- a formação continuada é uma exigência da formação profissional;

- a formação continuada deve ter como referência a prática docente e o conhecimento teórico;

- a formação continuada ultrapassa propostas de cursos de atualização e treinamento;

- a formação para ser continuada deve integrar-se ao dia a dia das escolas (BRASIL, 2005, p. 29-25).

Assim, percebemos que há uma preocupação institucionalizada com a formação de professores em âmbito nacional, instituída como política por meio dos Programas de Formação Continuada. No caso deste estudo, reconhecemos o Programa Anual de Capacitação Continuada, fomentando a formação de sujeitos envolvidos nos cursos da modalidade EaD.

Além disso, a criação da Rede Nacional de Formação Continuada marca a organização administrativa do Estado quando estabelece este espaço para organizar e conduzir as políticas de formação. A partir dos relatos produzidos neste estudo, porém, percebemos que a Formação Continuada está para além de uma estrutura organizacional predefinida com objetivos e metas a serem alcançadas.

Este processo se dá com os professores e para os professores a partir do reconhecimento de suas necessidades laborais, instrumentalizando, dialogando, estimulando o repensar da prática, mas respeitando as reais necessidades do profissional para que o espaço formativo se torne um local de fortalecimento e novos aprendizados efetivos para o desenvolvimento da profissão.

Para finalizar, entendemos que os saberes docentes são constituídos na relação entre teoria e prática. Este é o resultado de um longo processo de constituição do ser docente e de seu perfil profissional. Assim: 
Na construção da atividade do docente busca-se reelaborar os saberes inicialmente tomados como verdades, em confronto com as descrições das práticas cotidianas que se tornam auxiliares nesse processo e em relação à teoria didática. Este processo de descrever as práticas cotidianas configura um processo essencialmente reflexivo (PIMENTA; ANASTASIOU, 2005, p. 113).

\section{CONSIDERAÇÕES FINAIS}

O estudo proposto teve como objetivo identificar as percepções dos tutores a distância do curso de Graduação em Administração modalidade EaD sobre as motivações e reflexões geradas pela participação em atividades de formação continuada. A pesquisa nos mostrou que os tutores participam ativamente das formações promovidas pela SEaD, reconhecem a contribuição desse aprendizado, mas não se reconhecem nas discussões pedagógicas. As formações de uso das ferramentas do Moodle, bem como as ações de caráter prático como o feedback, foram ressaltadas.

Escrita e avaliação também foram destacadas como um instrumental importante no desenvolvimento da atividade, mas esses tutores interrogam-se quanto à obrigatoriedade da formação. Percebemos o pertencimento de discurso sobre formação quando o tutor interagia com o professor titular da disciplina, assim como em outros espaços do curso, compartilhando conhecimentos da área de atuação.

Verificamos ainda um discurso dúbio, em que o tutor discorre tranquilamente toda sua prática docente, como agente integrador de ação no processo educativo dentro da modalidade, mas confuso quando ao participar da formação continuada em EaD, deparando-se com temas geradores que fugiam de sua área de formação ou atuação.

A partir da análise dos discursos dos sujeitos podemos constatar que para estes a figura do tutor a distância é clara enquanto atuação, compreendendo atribuições e importância no processo de mediação. Também compreendem as ferramentas da EaD como essenciais para sua atuação, mas reforçam que os processos formativos devem ser repensados levando em consideração o formato e o público-alvo.

Os pesquisados não se reconhecem discutindo sobre Educação, mesmo estando inseridos nesse contexto. Sentem-se desconfortáveis por não entenderem alguns temas discutidos no processo formativo para atuação na $\mathrm{EaD}$, considerando-os irrelevantes para sua atuação como formadores dos futuros profissionais de Administração.

\section{REFERÊNCIAS}

BELLI, E. S.. Uma proposta de EaD para o curso técnico de secretariado. Florianópolis. 1999. Dissertação (Mestrado em Engenharia de Produção) - Universidade Federal de Santa Catarina, Florianópolis. 1999. Disponível em: teses.eps.ufsc.br/defesa/pdf/4213.pdf. Acesso em: 25 nov. 2014.

BELLONI, M. L. Educação a Distância. São Paulo: Autores associados, 2003.

BRASIL. Ministério da Educação. Portaria no 4.059, de 10 de dezembro de 2004. Dispõe sobre a regulamentação das atividades semi-presenciais. Disponível em: http://portal.mec.gov.br/sesu/arquivos/pdf/ nova/acs_portaria4059.pdf. Acesso em: 10 abr. 2016.

BRASIL. Ministério da Educação. Resolução CD/FNDE no 26, de 5 de junho de 2009. Estabelece orientações e diretrizes para o pagamento de bolsas de estudo e de pesquisa a participantes da preparação e execução dos cursos dos programas de formação superior, inicial e continuada no âmbito do Sistema Universi- 
dade Aberta do Brasil (UAB), vinculado à Coordenação de Aperfeiçoamento de Pessoal de Nível Superior (Capes), a serem pagas pelo FNDE a partir do exercício de 2009. Disponível em: http://www.uab.capes. gov.br/images/stories/downloads/legislacao/resolucao_fnde_n26.pdf. Acesso em: 10 abr. 2016.

BRASIL. Ministério da Educação. Secretaria de Educação a distância. Referências de qualidade para a Educação Superior a distância. Brasília, ago. 2007. Disponível em: http://portal.mec.gov.br/seed/arquivos/ pdf/legislacao/refead1.pdf. Acesso em: 10 jun. 2015.

BRASIL. Decreto no 5.622, de 19 de dezembro de 2005. Regulamenta o art. 80 da Lei n.o 9.394, de 20 de dezembro de 1996, que estabelece as diretrizes e bases da educação nacional. Disponível em: http:// www.planalto.gov.br/ccivil_03/_Ato2004-2006/2005/Decreto/D5622.htm. Acesso em: 21 mar. 2015.

BRASIL. Ministério da Educação. Secretaria de Ensino Médio. Parâmetros Curriculares Nacionais: ensino médio. Lei de Diretrizes e Bases da Educação Nacional (Lei n. 9.394/96). Brasília: MEC/SEMT, 1999, p. 39-57.

BRUNO, A. R.; LEMGRUBER, M. S. Dialética professor-tutor na educação on-line: o curso de Pedagogia UAB-UFJF em perspectiva. In: ENCONTRO NACIONAL SOBRE HIPERTEXTO, 3., 2009, Belo Horizonte, MG. Anais [...]. Recife: Universidade Federal de Pernambuco, 2009. Disponível em: http://www.ufpe.br/nehte/hipertexto2009/anais/a/a-dialetica-professor-tutor.pdf. Acesso em: 2 jun. 2015.

CONTRERAS, J. A autonomia de professores. Editora Cortez: São Paulo-SP, 2002.

CORTES, S. M. V. Técnicas de coleta e análise qualitativa dos dados. Cadernos de Sociologia, Porto Alegre, v. 9, p. 11-47, 1998.

CUNHA, A. L. Interação verbal em fóruns de discussão: a língua escrita em atividades colaborativas. Disponível em http://www.abed.org.br/congresso2007/tc/415200753049PM.pdf. Acesso em: 5 maio 2016.

CUNHA, S. L. S. Reflexões sobre o EAD no Ensino de Física. Revista Brasileira de Ensino de Física, São Paulo, v. 28, n. 2, p. 151-153, 2006.

EMERENCIANO, M. S. J.; SOUSA, C. A. L.; FREITAS, L. G. Ser presença como educador, professor e tutor. In: CONGRESSO BRASILEIRO DE EDUCAÇÃO A DISTÂNCIA, 8., 2001, Brasília. Anais [...]. Brasília: Associação Brasileira de Educação a Distância, 2005. Disponível em: http://www.abed.org.br/congresso2005/por/pdf/032tcd5.pdf. Acesso em: 3 maio 2015.

FURG. Secretaria Geral de Educação a Distância. Edital 05/2016 - Seleção de tutor bolsista. 2016. Disponível em: http://www.sead.furg.br/index.php/editais/cat_view/305-adm-edital-052016. Acesso em: 23 maio 2016.

LEFÈVRE, F.; LEFÈVRE, A. M. C. Pesquisa de representação social: um enfoque qualiquantitativo à metodologia do discurso do sujeito coletivo. Brasília: Liber Livro, 2012. (Série Pesquisa, 20).

LOPES, J. P. Educação a distância e constituição da docência. Interação - Revista da Faculdade de Educação da UFG. Goiânia, v. 35, n. 2, jul./dez., p. 275-291, 2010.

MANSELL, R.; TREMBLAY, G. Renovando a visão das sociedades do conhecimento para a paz e o desenvolvimento sustentável. Organização das Nações Unidas para a Educação, a Ciência e a Cultura - UNESCO. Trad. M. Nicolosi e G. Pugliesi Sachs. São Paulo: Comitê Gestor da Internet no Brasil, 2015. Disponível em: http://unesdoc.unesco.org/images/0023/002325/232575por.pdf. Acesso em: 6 nov. 2015.

MATTAR, J. Tutoria e interação em educação a distância. São Paulo: Cengage Learning, 2012. (Série Educação e Tecnologia).

MATURANA, H. R. Emoções e linguagem na educação e na política. Belo Horizonte: UFMG, 2005.

MINAYO, M. C. O desafio do conhecimento: pesquisa qualitativa em saúde. São Paulo: Hucitec, 1998.

MOORE, M.; KEALSLEY, G. A Educação a Distância: uma visão integrada. São Paulo: Thomson Learning, 2007.

MONTEIRO, A. F. et al. Tutoria a distância: afetiva e efetiva. In: JELINEK, K. R.; VANIEL, B. V. (org.). Tutor/ autor: experiências e saberes. Rio Grande: Ed. da Furg, 2013.

MORAES, M. de. A monitoria como serviço de apoio ao aluno na educação a distância. 2004. 229f. Tese (Doutorado em Engenharia de Produção) - Programa de Pós-Graduação em Engenharia de Produção, Universidade Federal de Santa Catarina, Florianópolis, 2004. Disponível em: https://repositorio.ufsc.br/ xmlui/bitstream/handle/123456789/87894/204494.pdf?sequence=1TESE!\%20/0. Acesso em: 15 abr. 2015.

MORAN, J.; MASSETO, M.; BEHRENS, M. Novas tecnologias e mediação pedagógica. Campinas, SP: Papirus, 2000.

NEVES, C. E. B.; CORRÊA, M. B. Apresentação. In: NEVES, C. E. B.; CORRÊA, M. B. (org.). Pesquisa social empírica: métodos e técnicas. Porto Alegre, 1998, p. 8. (Cadernos de Sociologia). 
NOGUEIRA, V. A linguagem escrita na educação a distância: possibilidades de comunicação e constituição do sujeito/aluno. Disponível em: http://w3.ufsm.br/kosmos/textos/vanessa_endipe.pdf. Acesso em: 10 mar. 2016

NOVELLO, T. P. Cooperar no atuar de professores e tutores. 2011. Tese (Doutorado em Educação Ambiental) - Programa Pós-Graduação em Educação Ambiental, Universidade Federal do Rio Grande, Rio Grande, 2011.

NÓVOA, A. O Passado e o presente dos professores. In: NÓVOA, A. (org). Profissão professor. 2. ed. Portugal: Porto, 1999. p. 13-34.

OLIVEIRA, C. L. A. P. Afetividade, aprendizagem e tutoria on-line. Disponível em: http://www.anped.org. br/reunioes/32ra/arquivos/trabalhos/GT16-5141--Int.pdf. Acesso em: 12 set. 2014.

OLIVEIRA, G. M. S. de. A avaliação no sistema de educação a distância. 2006. Disponível em: http://www. uab.ufmt.br/uab/images/artigos_site_uab/avaliacao_sistema_ead.pdf. Acesso em: 22 jan. 2016.

SAGGIOMO, L. S. Percepções, sentidos e sentimentos do professor tutor na formação continuada em Educação a Distância. 2016. Dissertação (Mestrado em Educação em Ciências) - Programa de Pós-Graduação de Educação em Ciência: Química da Vida e Saúde, Universidade Federal do Rio Grande, Rio Grande, 2016.

SALES, F.; SOUZA, F. C.; JOHN, V. M. O emprego da Abordagem DSC (Discurso do Sujeito Coletivo) na pesquisa em Educação. Revista Linhas, Florianópolis, v. 8, n. 1, p. 124-145, jan./jun. 2007. Disponível em: http://www.periodicos.udesc.br/index.php/linhas/article/viewFile/1361/1167. Acesso em: 18 set. 2016. SILVA, M. Sala de aula interativa. 4.ed. Rio de Janeiro: Quartet, 2006.

SOUZA, C. H. M. de. Comunicação, educação e novas tecnologias. Campos dos Goytacazes, RJ: Editora Fafic, 2003.

TARDIF, M. Saberes docentes e formação profissional. 16. ed. Petrópolis: Vozes, 2014.

VILARINHO, L. R. G.; CABANAS, M. I. C. Educação a Distância (EaD): o tutor na visão de tutores. Revista Educação, Santa Maria, v. 33, n. 3, p. 481-494, set./dez. 2008. Disponível em: http://www.ufsm.br/revistaeducação. Acesso em: 19 mar. 2015.

WILLIAMS, R. L. Preciso saber se estou indo bem: uma história sobre a importância de dar e receber feedback. Rio de Janeiro: Sextante, 2005. 